\title{
Molecular dynamics study on diamond nanowires mechanical properties: Strain rate, temperature and size dependent effects
}

\author{
Jing Guo a,b, Bin Wen ${ }^{\mathrm{a}, *}$, Roderick Melnik ${ }^{\mathrm{c}, \mathrm{d}}$, Shan Yao ${ }^{\mathrm{e}}$, Tingju $\mathrm{Li}^{\mathrm{e}}$ \\ a State Key Laboratory of Metastable Materials Science and Technology, Yanshan University, Qinhuangdao 066004, China \\ b Technical Center, BenXi Iron \& Steel (Group) Co., Ltd., China \\ ${ }^{c} M^{2}$ NeT Lab, Wilfrid Laurier University, Waterloo, 75 University Ave. West, Ontario, Canada N2L 3C5 \\ d BCAM, Bizkaia Technology Park, 48160 Derio, Spain \\ e School of Materials Science and Engineering, Dalian University of Technology, Dalian 116023, China
}

\section{A R T I C L E I N F O}

\section{Article history:}

Received 5 August 2010

Received in revised form 9 February 2011

Accepted 28 February 2011

Available online 4 March 2011

\section{Keywords:}

Mechanical properties

Diamond nanowires

Strain rates

Size effects

Temperature dependent properties

Molecular dynamics

Atomistic methods

\begin{abstract}
A B S T R A C T
Using molecular dynamics simulations, strain rate, temperature and size dependent mechanical properties of $<001>$ orientation diamond nanowires are investigated. It is found that, for the same cross-sectional areas, strain rates have almost no effect on yield strength and Young's modulus, provided strain rates are within the range from 0.001 to $0.025 \mathrm{ps}^{-1}$. Our calculated results have also indicated that, at the temperature ranging from 100 to $500 \mathrm{~K}$, diamond nanowires' yield strength, Young's modulus, fracture strength and fracture strain are all decreasing with increasing temperature. Furthermore, at the temperature of $300 \mathrm{~K}$, yield strength, Young's modulus, fracture strength and fracture strain increase dramatically with increasing cross sectional area. Finally, orientation dependent diamond nanowires mechanical properties are studied.
\end{abstract}

(C) 2011 Elsevier B.V. All rights reserved.

\section{Introduction}

Diamond nanowires (DNWs) were fabricated firstly by Shiomi in 1997 [1], and many methods [2-12] were developed to fabricate DNWs after that. Due to their unique properties and a wide range of current and potential applications [2,13-20], DNWs have attracted much attention in recent years and a number of theoretical and experimental efforts have recently been carried out in order to better understand the properties of DNWs.

For example, the energy band structure of DNWs has been investigated by first principles calculations by Barnard in 2004 [21]. The crystalline structure of DNWs has been studied by first principle calculations by Okada in 2009 [22]. Thermal conductivities of DNWs have been studied by molecular dynamics simulations by Moreland et al. [23], Padgett et al. [24], and Guo et al. [25], in 2004, 2006 and 2010, respectively. Electrochemical properties of DNWs have been studied experimentally by Nebel et al. in 2009 [10]. Optical properties of DNWs have been studied by Thomas et al. in 2010 [26].

Due to potential applications of DNWs in chemical and biochemical sensing, enhancements in thermal management, mechanical reinforcement and electro-mechanical devices, the mechanical prop-

\footnotetext{
* Corresponding author.

E-mail address: wenbin@ysu.edu.cn (B. Wen).
}

erties of DNWs are becoming an increasingly important area of study. Although many works were performed to understand the mechanical properties for other nanodiamond structures (e. g. films, particles etc.) [27-33], the research results on the mechanical properties of DNWs are scarce in the literature. To fill this gap, in this work the mechanical properties have been studied by using molecular dynamics (MD) simulations, and the effects of strain rate, size and temperature on DNWs mechanical properties have been analyzed in detail.

\section{Computational method}

In this work, hydrogen-terminated one dimensional DNWs of $<001>$ orientation have been studied. To gain insights into mechanical properties of DNWs, classical MD simulations were used to carry out DNWs tensile tests [34]. All the properties were obtained as time averages over the particle positions and velocities. The MD simulations have been performed by employing the widely used Large-scale Atomic/ Molecular Massively Parallel Simulator (LAMMPS) package [35]. The interactions between atoms were described by the Adaptive Intermolecular Reactive Empirical Bond Order (AIREBO) potential [36]. These interactions have strong coordination dependence through a bond order parameter, and the inter-atomic forces used in the simulations were modeled by a many-body bond order function.

A schematic representation of the system we simulate is shown in Fig. 1(a). Firstly, the DNWs are relaxed to their equilibrium states at a 


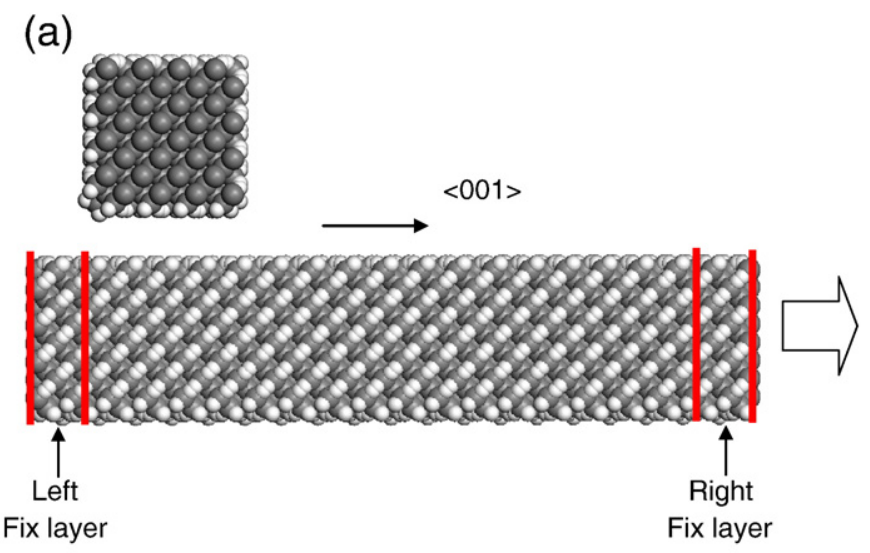

(b)

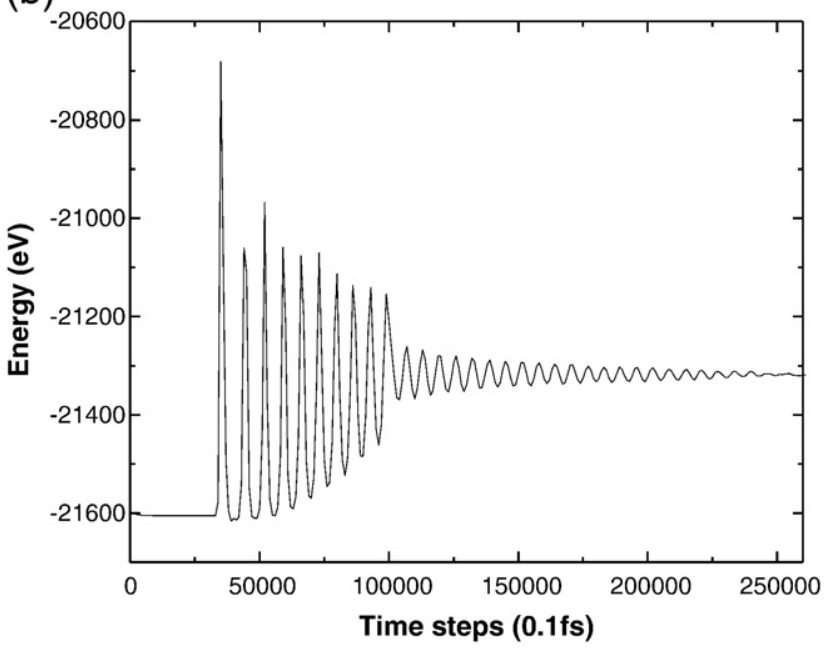

Fig. 1. (a) A schematic representation of the simulated DNWs, (b) Convergence dynamics to reach the steady state for DNWs at $300 \mathrm{~K}$.

specified temperature and while being free of tensile strain, and then the DNWs are relaxed under tensile strain by moving the end atoms. In this work, the isothermal-isobaric (NPT) ensemble is used, and the pressure is atmospheric pressure. For the relaxation of DNWs under no tensile strain, the simulation step time is $0.1 \mathrm{fs}$. The entire simulation time is $24 \mathrm{ps}$, that is $2.4 \times 10^{5} \mathrm{MD}$ steps. To ensure the equilibrium, we obtained the total energy vs simulation time in the temperature of $300 \mathrm{~K}$. Fig. 1(b) shows a relationship between the whole energy and simulation time (or time steps) for DNWs at $300 \mathrm{~K}$. This result indicates that $2.4 \times 10^{5} \mathrm{MD}$ steps are sufficient to reach the steady state for the total energy (similar results hold true for all DNWs studied in this work).

After DNWs reach the steady state under no tensile strain conditions, an axial strain along the $<001>$ orientation is applied at a special strain rate $\Delta \varepsilon z$. Therefore, strain $\varepsilon z$ at simulation step nstep can be written as:

$\varepsilon z=\Delta \varepsilon z \cdot \Delta t \cdot n s t e p$

where $\Delta \varepsilon z$ is the strain rate, $n s t e p$ is the number of relaxation steps, $\Delta t$ is the simulation step time.

At the same time, the axial stress at simulation step nstep can be deduced by computing the arithmetic mean of the local stress on all the atoms [37]. It is expressed as:

$\sigma_{z}(\varepsilon)=\frac{1}{\Omega} \sum_{i=1}^{n} \sum_{\substack{j=1 \\ j \neq i}}^{n} F_{z}^{i j}(\varepsilon) r_{z}^{i j}(\varepsilon)$,

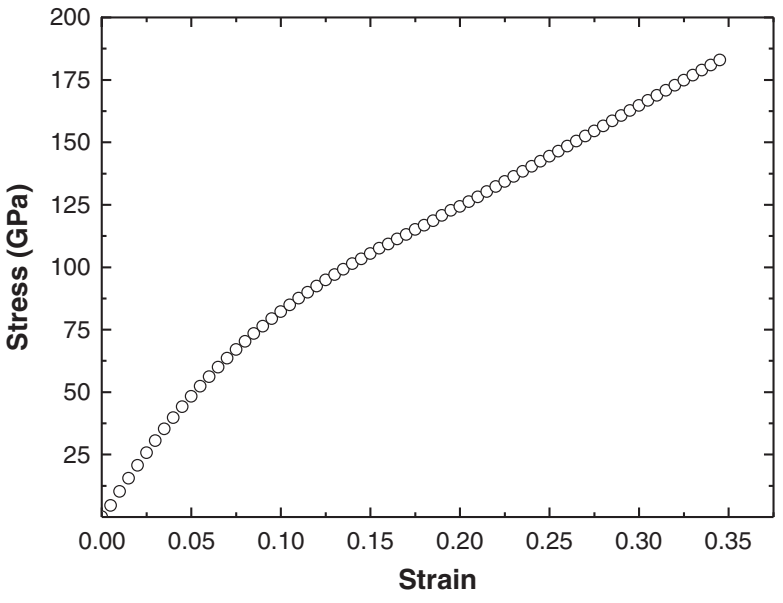

Fig. 2. Stress vs strain curves for bulk diamond with $<001>$ crystal orientation at $300 \mathrm{~K}$.

where $n$ represents the number of atoms, $F_{z}^{i j}$ represents the $<001>$ direction component of the pairwise interatomic force between atoms $i$ and $j, r_{z}^{i j}$ is the interatomic distance in the $<001>$ direction between the $(i, j)$ pair, $\Omega$ refers to the system volume. Finally, stress-strain curves of DNWs are obtained by plotting the relationship between strain and the corresponding stress, and then the Young's moduli are obtained from the slope of the linear portion of such stress-strain curves.

To verify the accuracy of our current computational method, stress versus strain curves in the $<001>$ orientation crystal of bulk diamond at $300 \mathrm{~K}$ have been analyzed by using the above methodology, and they are shown in Fig. 2. The Young's modulus can be obtained by calculating the slope of the straight line in the elastic region (up to 3\%). In Table 1 and Fig. 3, the calculated Young's modulus is compared with experimental and other theoretical [33,38-40] data, the calculated Young's modulus agrees perfectly well with experimentally and other theoretically reported results. Such an agreement demonstrates that the computational methodology and parameters used in this work are appropriate and that the mechanical properties from our calculations are reliable. We also note that similar methodologies have already been applied successfully to the analysis of the mechanical behaviors of several other nanostructures [34,37,41-43].

\section{Results and discussions}

\subsection{Strain rate effect on mechanical properties}

To study strain rate effects on mechanical properties, stress-strain curves of DNWs with cross-sectional areas of $4.58 \mathrm{~nm}^{2}$ have been investigated. The simulated temperature has been set as $300 \mathrm{~K}$, and the strain rates have been ranging from 0.001 to $0.025 \mathrm{ps}^{-1}$. Fig. 4 shows the relationship between computed stresses and strain under different strain rates conditions. It can be seen that all DNWs yield strengths and Young's moduli are less affected by strain rates within the strain rates range studied in this work. In particular, the Young's

Table 1

Calculated Young's modulus compared to experimental and other theoretical values for single-crystal diamond.

\begin{tabular}{ll}
\hline Diamond & Young's modulus (GPa) \\
\hline Jiang [33] & 1004 \\
Paci [38] & 1090 \\
Shenderova [39] & 1052 \\
Hess [40] & 1143 \\
This work & 1014 \\
\hline
\end{tabular}




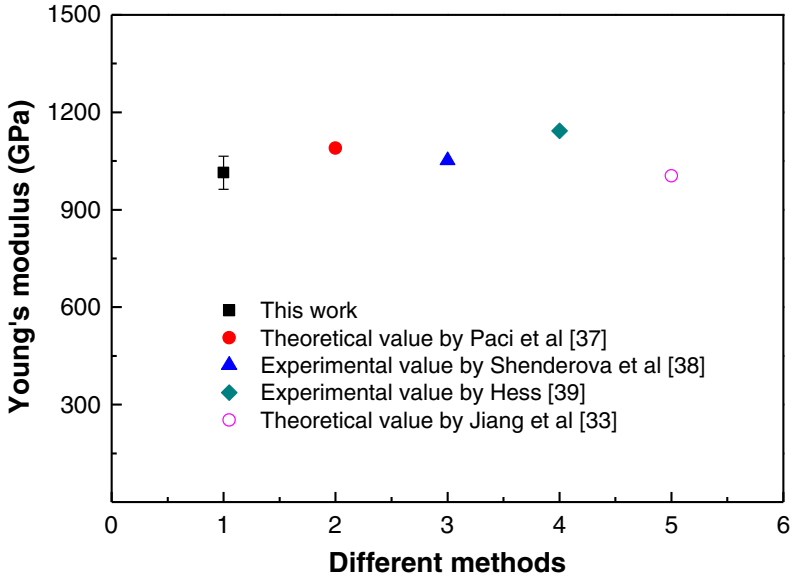

Fig. 3. Calculated Young's modulus compared to experimental and other theoretical values for bulk single-crystal diamond.

modulus is $688 \mathrm{GPa}$ and the yield strength is $63 \mathrm{GPa}$. Note also that the Young's modulus of DNWs determined here is lower than that of bulk diamond (1014 GPa).

\subsection{Temperatures effect on mechanical properties}

Temperature effects have been shown to be an important factor in defining correctly key properties of low dimensional nanostructures [44]. In order to analyze the temperature effect on mechanical properties, DNWs with cross-sectional areas of $4.58 \mathrm{~nm}^{2}$ have been investigated. In this analysis, the strain rate has been $0.001 \mathrm{ps}^{-1}$, and the temperature has been ranging from 100 to $500 \mathrm{~K}$. Fig. 5 shows temperature dependent stress-strain responses. To analyze this in detail, temperature dependent yield strength and Young's modulus have been determined from the corresponding stress-strain responses by using a linear regression, and they are shown in Fig. 6 (a) and (b), respectively. All details on mechanical property values are summarized in Table 2. Observe that in Figs. 5 and 6, with increasing temperature, DNWs yield strength and Young's modulus are decreasing. Specifically, with the temperature increase from 100 to $500 \mathrm{~K}$, Young's modulus has a $28.3 \%$ drop and the yield strength has a $29.8 \%$ drop, respectively. As can be seen from Table 2 and Fig. 6, when the temperature is $100 \mathrm{~K}$, the yield strength is $74 \mathrm{GPa}$ and the Young's modulus is $831 \mathrm{GPa}$. Note also that when the temperature is $500 \mathrm{~K}$, the yield strength is $53 \mathrm{GPa}$ and the Young's modulus is $583 \mathrm{GPa}$. It can be seen that the Young's modulus

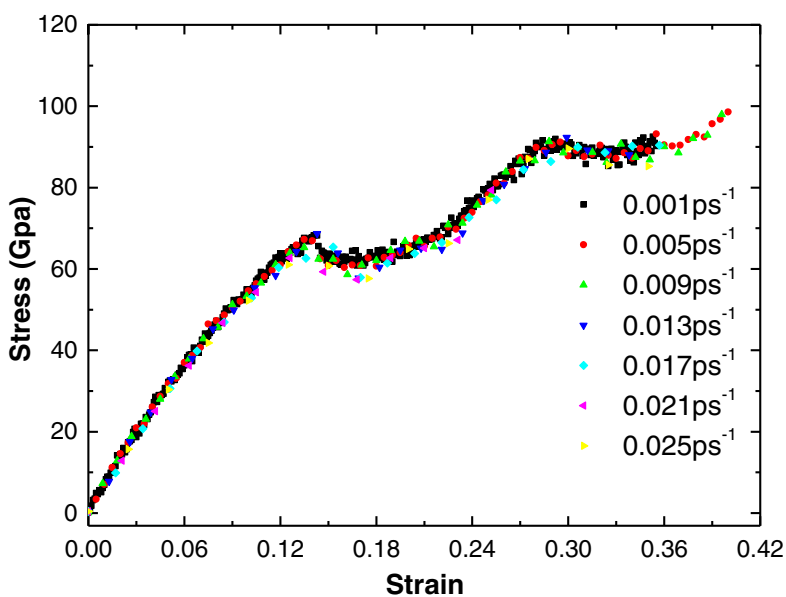

Fig. 4. Stress-strain responses with strain rate ranging from 0.001 to $0.025 \mathrm{ps}^{-1}$ at cross sectional area of $4.58 \mathrm{~nm}^{2}$ and temperature of $300 \mathrm{~K}$.

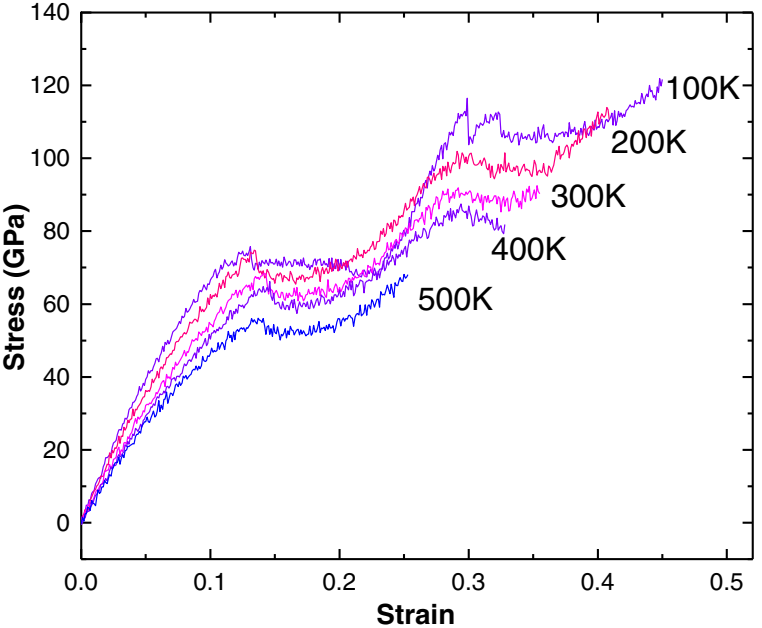

Fig. 5. Stress-strain responses with temperature ranging from 100 to $500 \mathrm{~K}$ for DNWs with cross sectional area of $4.58 \mathrm{~nm}^{2}$.

and yield strength decrease monotonically with increasing temperature. It also indicates that the fracture strength and fracture strain decrease with increasing temperature. When the temperature is $100 \mathrm{~K}$, the fracture strength and fracture strain are $122 \mathrm{GPa}$ and 0.45 , respectively,

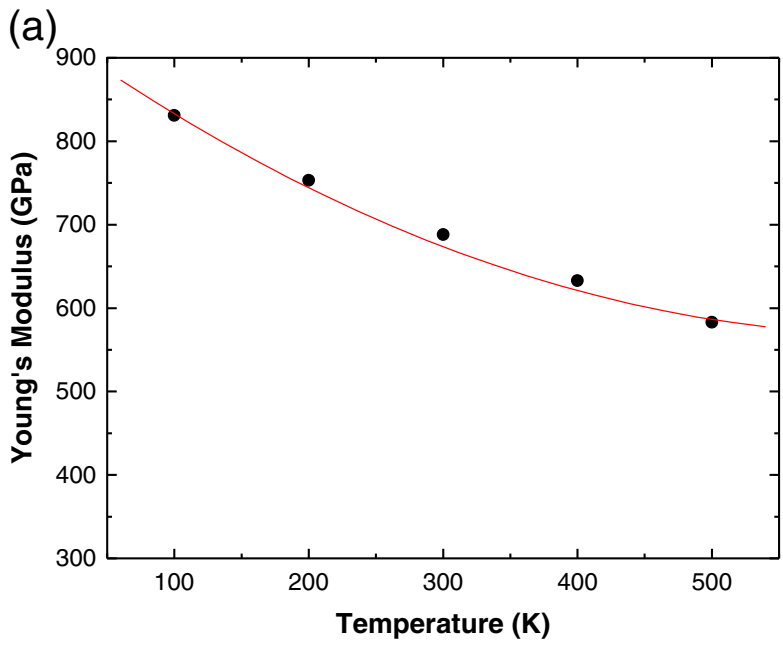

(b)

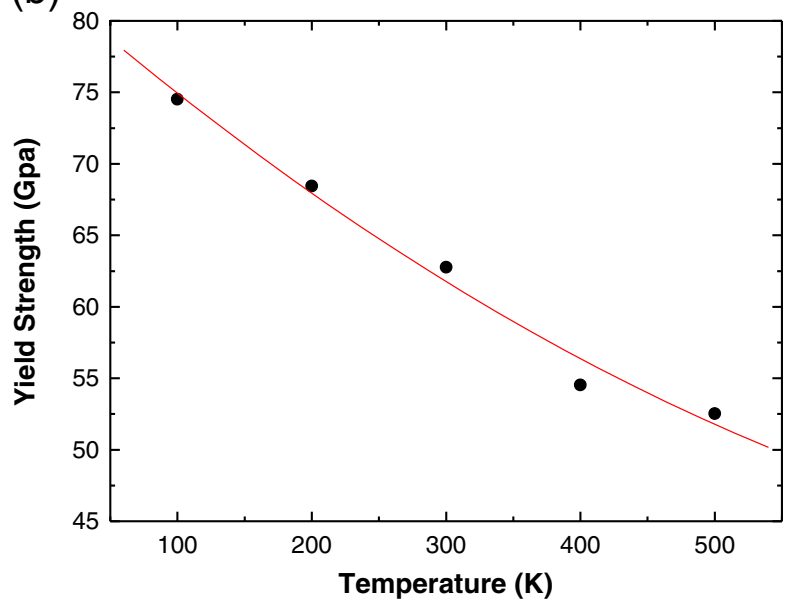

Fig. 6. Variations of the yield strength (a) and Young's modulus (b) with temperature increasing from 100 to $500 \mathrm{~K}$; DNWs cross-sectional area is $4.58 \mathrm{~nm}^{2}$. 
Table 2

Calculated mechanical properties at different temperature conditions for DNWs' crosssectional areas of $4.58 \mathrm{~nm}^{2}$.

\begin{tabular}{lccccc}
\hline Temperature (K) & 100 & 200 & 300 & 400 & 500 \\
\hline Yield strength (GPa) & 74 & 68 & 63 & 54 & 53 \\
Young's modulus (GPa) & 831 & 753 & 688 & 633 & 583 \\
Fracture strength (GPa) & 122. & 112 & 91 & 80 & 68 \\
Fracture strain & 0.45 & 0.41 & 0.35 & 0.31 & 0.25 \\
\hline
\end{tabular}

whereas when the temperature is $500 \mathrm{~K}$, the fracture strength and fracture strain become $68 \mathrm{GPa}$ and 0.25 , respectively.

To further understand the mechanism of Young's modulus and yield strength decrease monotonically with temperature, total energies as a function of strain have also been computed at different temperatures, and they are shown in Fig. 7. With increasing temperature, the total energy increases, and then the structural stability decreases. This may account to the Young's modulus and yield strength monotonic decrease with temperature.

\subsection{Cross-sectional area effect on mechanical properties}

Next, at the temperature of $300 \mathrm{~K}$, cross sectional area dependent tensile strain of DNWs has also been investigated. The cross sectional areas analyzed here have been ranging from $2.04 \mathrm{~nm}^{2}$ to $12.72 \mathrm{~nm}^{2}$, and the strain rate has been $0.001 \mathrm{ps}^{-1}$. Fig. 8 shows the cross sectional area dependent stress-strain curves, and details on mechanical property values are summarized in Table 3. It can be seen that the yield strength and Young's modulus increase dramatically with increasing cross sectional area, and the values are lower than those of bulk. As shown in Table 3, the cross sectional area increase from 2.04 to $12.72 \mathrm{~nm}^{2}$, will amount for $175.8 \%$ in yield strength increase and $99.7 \%$ in Young's modulus respectively. Figs. 9 (a) and (b) show the variations trend of the Young's modulus and yield strength as a function of the cross sectional area. As can be seen, the Young's modulus of DNWs increases as its cross sectional area becomes larger. It is expected that, as the cross sectional area increases, the Young's modulus will eventually approach the value of bulk diamond ( $E_{\text {bulk }}=1014 \mathrm{GPa}$ ). An exponential formula can be fitted to describe the relationship between the cross sectional area and the Young's modulus, namely

$E=5851.8-4924.2 \cdot \exp \left(\frac{1}{5.2 A}\right)$

where $A$ is the cross sectional area (in $\mathrm{nm}^{2}$ ), $E$ is the Young's modulus (in GPa).

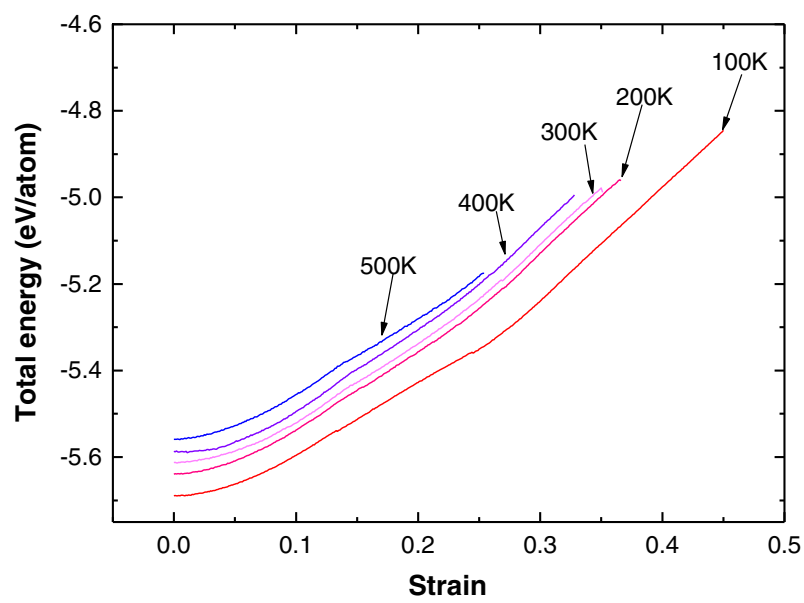

Fig. 7. Total energy curves as a function of strain at different temperatures.

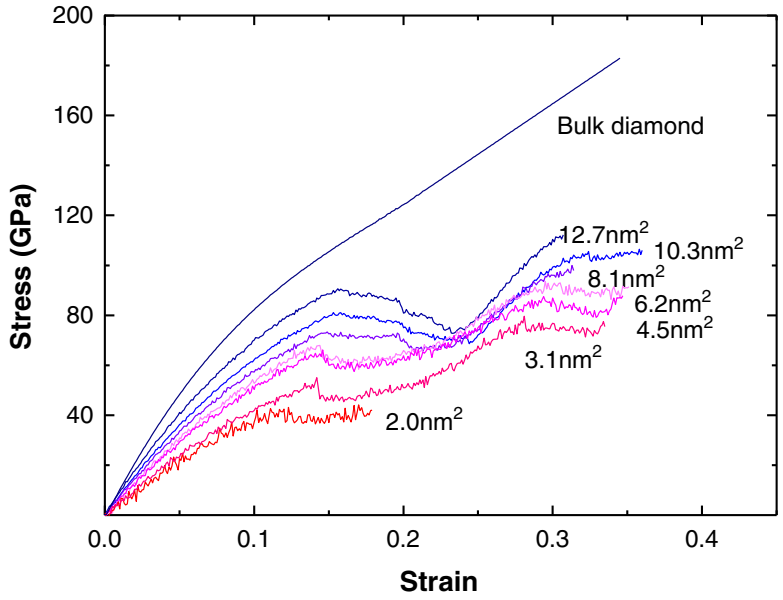

Fig. 8. Stress-strain curves with DNWs cross sectional areas ranging from $2.04 \mathrm{~nm}^{2}$ to $12.72 \mathrm{~nm}^{2}$ at $300 \mathrm{~K}$

The above trend can be explained based on the state of stress in the stable structure of diamond nanowires. Surface stress is inversely related to the cross sectional area of the nanowires $[42,45]$. The surface stress induced compressive pressure is very small and the surface effects are insignificant when the cross sectional area is sufficiently large.

\subsection{Orientation effect on mechanical properties}

Finally, crystal orientations dependent tensile strains of DNWs have also been investigated. Three crystal orientations DNWs have been considered, that is $<001>,<011>$ and $<111>$ crystal orientations. All DNWs cross-sectional areas considered here are about $4.58 \mathrm{~nm}^{2}$. The relationships between crystal orientations and stress-strain responses for these three crystal orientations DNWs are shown in Fig. 10. It can be seen that DNWs yield strength and Young's modulus are disparate with different crystal orientations. For $<001>$ crystal orientation DNWs, the yield strength is $63 \mathrm{GPa}$ and the Young's modulus is $688 \mathrm{GPa}$. However, for $<011>$ crystal orientation DNWs, Young's modulus has a 74.7\% drop and the yield strength has a $77.8 \%$ drop, respectively. For $<111>$ crystal orientation DNWs, it will amount for $47.7 \%$ in yield strength increase and $0.8 \%$ in Young's modulus respectively. In particular, Young's modulus in $<111>$ crystal orientation is significantly larger than in $<001>$ and $<011>$ crystal orientations. It has also indicated that Young's modulus in all DNWs considered here are lower than those of bulk diamond.

\section{Conclusions}

In summary, mechanical properties of hydrogen-terminated diamond nanowires with $<001>$ crystal orientations were investigated by using molecular dynamics simulations. Our calculated results indicated

Table 3

Variations of mechanical properties of DNWs with cross sectional area ranging from 2 to $12.7 \mathrm{~nm}^{2}$ at temperature of $300 \mathrm{~K}$.

\begin{tabular}{lcccc}
\hline $\begin{array}{l}\text { Cross sectional } \\
\text { area }\left(\mathrm{nm}^{2}\right)\end{array}$ & $\begin{array}{l}\text { Yield } \\
\text { strength } \\
(\mathrm{GPa})\end{array}$ & $\begin{array}{l}\text { Young's } \\
\text { modulus } \\
(\mathrm{GPa})\end{array}$ & $\begin{array}{l}\text { Fracture } \\
\text { strength } \\
(\mathrm{GPa})\end{array}$ & $\begin{array}{l}\text { Fracture } \\
\text { strain }\end{array}$ \\
\hline 2.0 & 29 & 425 & 45 & 0.19 \\
3.2 & 55 & 635 & 74 & 0.31 \\
4.6 & 63 & 688 & 82 & 0.33 \\
6.2 & 72 & 764 & 91 & 0.34 \\
8.1 & 75 & 825 & 98 & 0.31 \\
10.3 & 79 & 834 & 106 & 0.35 \\
12.7 & 80 & 849 & 111 & 0.31 \\
Bulk diamond & 183 & 1014 & 183 & 0.35 \\
\hline
\end{tabular}


(a)

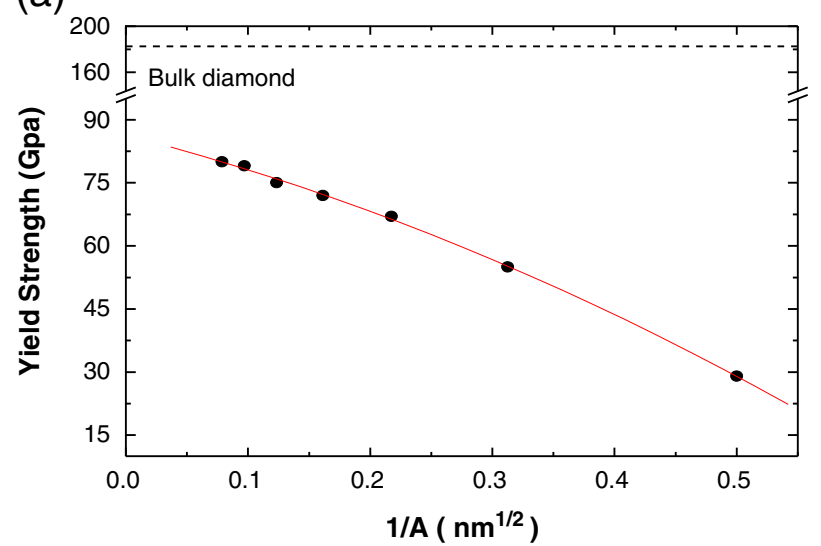

(b)

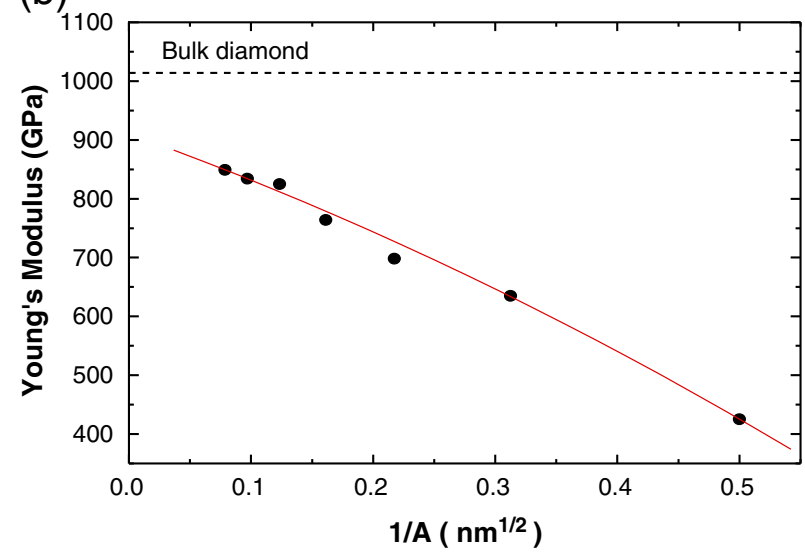

Fig. 9. Variations of the yield strength (a) and Young's modulus (b) with the inverse of DNWs cross sectional area increasing from 2.04 to $12.72 \mathrm{~nm}^{2}$.

that within strain rates ranging from 0.001 to $0.025 \mathrm{ps}^{-1}$, strain rates have almost no effect on yield strength and Young's modulus. It was also found that the yield strength and Young's modulus are decreasing with increasing temperature from $100 \mathrm{~K}$ to $500 \mathrm{~K}$. In addition, at the same temperature conditions, the yield strength and Young's modulus increase dramatically with increasing cross sectional area, gradually

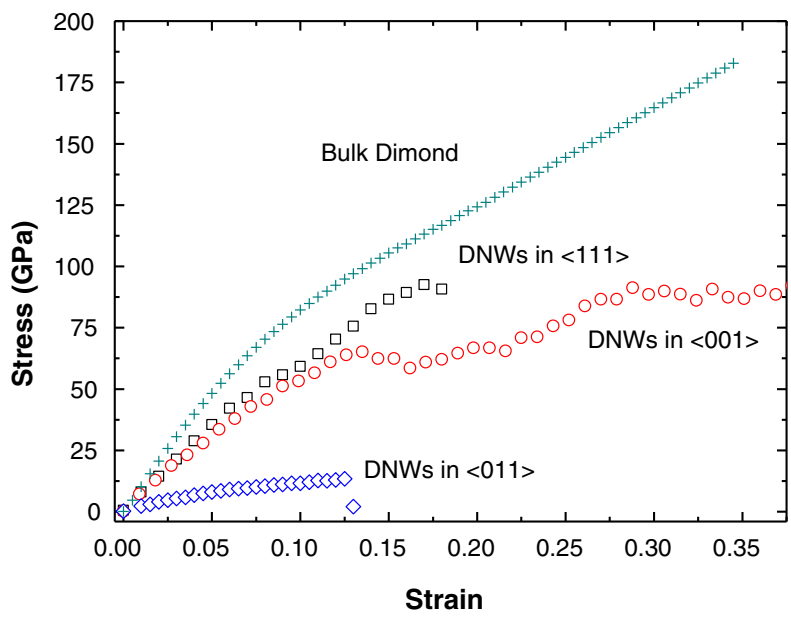

Fig. 10. Stress-strain curves with DNWs in $<111>,<001>$ and $<011>$ crystal orientations at $300 \mathrm{~K}$. Also shown are data of bulk diamond computed in this simulation. approaching the value of bulk diamond. Finally, orientation dependent diamond nanowires mechanical properties were analyzed.

\section{Acknowledgments}

This work was supported by the National Natural Science Foundation of China (Grants 50772018, and 50402025) and the Program for New Century Excellent Talents in Chinese Universities (NCET-07-0139). R. M. acknowledges the support from the NSERC and CRC program. This work was made possible by the facilities of the Shared Hierarchical Academic Research Computing Network (SHARCNET), Canada.

\section{References}

[1] H. Shiomi, Japanese Journal of Applied Physics 36 (1997) 7745.

[2] E.S. Baik, Y.J. Baik, S.W. Lee, D. Jeon, Thin Solid Films 377 (2000) 295

[3] L.T. Sun, J.L. Gong, Z.Y. Zhu, Diamond and Related Materials 14 (2005) 749.

[4] Y.S. Zou, Y.T. Yang, W.J. Chong, Applied Physics Letters 92 (2008) 053105.

[5] W. Smirnov, A. Kriele, N. Yang, C.E. Nebel, Diamond and Related Materials 19 (2010) 186.

[6] H. Masudda, M. Watanabe, K. Yasui, Advanced Materials 12 (2000) 444.

[7] Q.X. Liu, C.X. Wang, S.W. Li, J.X. Zhang, G.W. Yang, Carbon 42 (2004) 629.

[8] A.R. Sobia, G.J. Yu, X.T. Zhou, A. Ishaq, D. Z Zhu, J. L. Gong, Journal of Crystal Growth 311 (2009) 3332.

[9] Y. Ando, Y. Nishibayashi, A. Sawabe, Diamond and Related Materials 13 (2004) 633.

[10] C.E. Nebel, N. Yang, H. Uetsuka, Diamond and Related Materials 18 (2009) 910.

[11] M. Davydov, A. Kromka, B. Rezek, O. Babchenko, M. Stuchlik, K. Hruska, Applied Surface Science 256 (2010) 5602.

[12] S. Szunerits, Y. Coffinier, E. Galopin, J. Brenner, R. Boukherroub, Electrochemistry Communications 12 (2010) 438.

[13] C.E. Nebel, B. Rezek, D. Shin, H. Uetsuka, N. Yang, Journal of Physics D: Applied Physics 40 (2007) 6443.

[14] N. Yang, H. Uetsuka, E. Osawa, C.E. Nebel, Nano letters 8 (2008) 3572.

[15] B. Wen, R.V.N. Melnik, Applied Physics Letter 92 (2008) 261911.

[16] B. Wen, J. J. Zhao, Global Journal of Physical Chemistry 2011 (in press).

[17] H. Uetsuka, T. Yamada, S. Shikata, Diamond and Related Materials 17 (2008) 728.

[18] M.Y. Chen, Y.K. Chih, J. Hwang, C.S. Kou, M.T. Chang, L.J. Chou, Thin Solid Films 516 (2008) 7595

[19] M.C. Kan, J.L. Huang, J. Sung, K.H. Chen, Thin Solid Films 187 (2004) 447.

[20] L. Diederich, O.M. Küttel, P. Aebi, L. Schlapbach, Surface Science 418 (1998) 219.

[21] A.S. Barnard, Reviews on Advanced Materials Science 6 (2004) 94.

[22] S. Okada, Chemical Physics Letters 483 (2009) 128.

[23] J.F. Moreland, J.B. Freund, G. Chen, Nanoscale and Microscale Thermophysical Engineering 8 (2004) 61.

[24] C.W. Padgett, O. Shenderova, D.W. Brenner, Nano letters 6 (2006) 1827.

[25] J. Guo, B. Wen, R. Melnik, S. Yao, T. Li, Physica E: Low-dimensional Systems and Nanostructures 43 (2010) 155.

[26] T.M. Babinec, B.J.M. Hausmann, M. Khan, Y. Zhang, J.R. Maze, P.R. Hemmer, M. Lončar, Nature nanotechnology 5 (2010) 195.

[27] S.Y. Luo, J.K. Kuo, B. Yeh, J.C. Sung, C.W. Dai, T.J. Tsai, Materials Chemistry and Physics 72 (2001) 133.

[28] L.P. Wang, Y. Gao, Q.J. Xue, H.W. Liu, T. Xu, Materials Science and Engineering A 390 (2005) 313.

[29] H. Sumiya, T. Irifune, Technical Review 59 (2005) 57.

[30] O. Shenderova, D.W. Brenner, R.S. Ruoff, Nano letters 3 (2003) 805.

[31] N. Dubrovinskaia, L. Durbrovinsky, W. Crichton, F. Langenhorst, A. Richter, Applied Physics Letters 87 (2005) 083106.

[32] C.W. Padgett, K.J. Gutt, T.S. Whiteside, Computational Materials Science 46 (2009) 491.

[33] X. Jiang, J.J. Zhao, C.Q. Zhuang, B. Wen, X. Jiang, Diamond and Related Materials 19 (2010) 21.

[34] S.J.A. Koh, P.H. Lee, Q.H. Cheng, Physical Review B 72 (2005) 085414.

[35] S. J. Plimpton, R. Pollock, M. Stevens, Particle-Mesh Ewald and rRESPA for Parallel Molecular Dynamics Simulations, Proc of the Eighth SIAM Conference on Parallel Processing for Scientific Computing, Machines, MN, 1997.

[36] S.J. Stuart, A.B. Tutein, J.A. Harrison, Journal of Chemical Physics 112 (2000) 6472.

[37] S.K.R.S. Sankaranarayanan, V.R. Bhethanabotla, B. Joseph, Physical Review B 76 (2007) 134117.

[38] J.T. Paci, T. Belytschko, G.C. Shatz, Chemical Physics Letters 414 (2005) 351

[39] O. Shenderova, D. Brenner, R.S. Ruoff, Nano Letters 3 (2003) 805

[40] P. Hess, Applied Surface Science 106 (1996) 429.

[41] S. Inoue, Y. Matsumura, Chemical Physics Letters 469 (2009) 125.

[42] A.J. Kulkarni, M. Zhou, F.J. Ke, Nanotechnology 16 (2005) 2749.

[43] S.P. Ju, J.S. Lin, W.J. Lee, Nanotechnology 15 (2004) 1221.

[44] S. Patil, R.V.N. Melnik, Nanotechnology 20 (2009) 125402.

[45] K. Gall, J. Diao, M.L. Dunn, Nano Letters 4 (2004) 2431. 